\title{
General thoracic surgical training in North America: Contrasting general thoracic surgery residencies in Canada and the United States
}

Colin Schieman, MD, ${ }^{\mathrm{a}}$ Christopher W. Seder, MD, ${ }^{\mathrm{b}}$ Thomas A. D'Amico, MD, ${ }^{\mathrm{c}}$ and Sean C. Grondin, MD, MPH ${ }^{\mathrm{a}}$

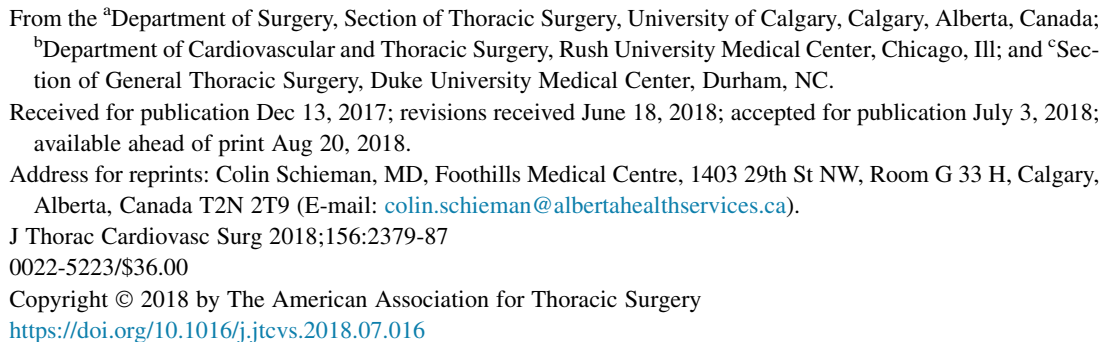

General thoracic surgery has a decorated history in North America. There are, however, key differences between the training systems in Canada and the United States. The purpose of this article is to compare and contrast the general thoracic surgery training provided in Canada and the United States and describe some of the challenges encountered by the American and Canadian systems. The terminology and nomenclature can be confusing when discussing both systems. In the United States, the terms "thoracic surgeon" and "cardiothoracic surgeon" are often used interchangeably, as graduates are qualified for independent practice in both general thoracic and cardiovascular surgery. However, in Canada the term "thoracic surgeon" refers specifically to a general thoracic surgeon who does not perform cardiac surgery. A summary of some of the key differences between the American and Canadian programs is included in Table 1.

\section{GENERAL THORACIC SURGERY TRAINING PROGRAM STRUCTURE \\ United States}

American cardiothoracic training programs are housed in a variety of settings, including university hospitals, academic-affiliated community hospitals, and government institutions. Each program is approved by the Accreditation Council on Graduate Medical Education (ACGME) to train a specific number of board-eligible residents per year. Some US programs with high volumes also have non-ACGMEaccredited "super fellows" who have already completed formal thoracic training.

Currently, 4 distinct cardiothoracic training paradigms are recognized by the ACGME and American Board of Thoracic Surgery (ABTS) and lead to board eligibility. Trainees have the option of entering one of the traditional (or "independent") programs (" $5+2$ " or " $5+3$ "), the Joint Training Programs (" $4+3$ "), or the Integrated (I-6) programs. In many circumstances, residents in different

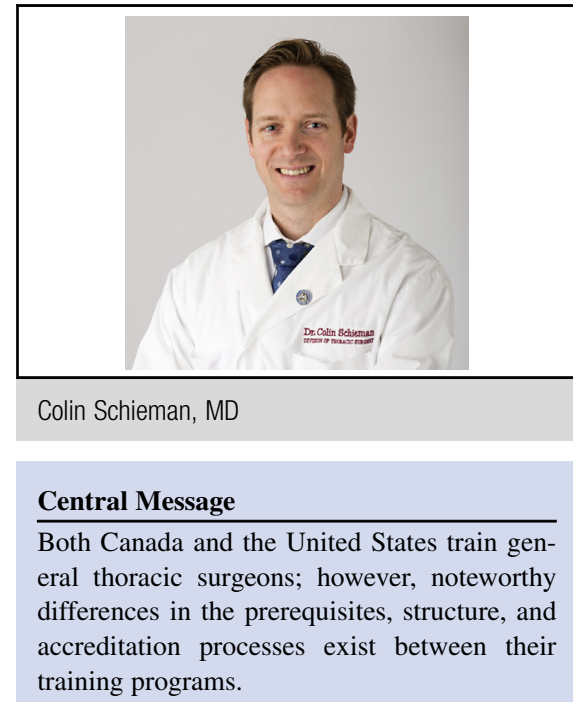

See Editorial Commentary page 2388.

cardiothoracic training paradigms exist within the same institution. Currently, there are 72 traditional $(5+2$ or 5 +3 ) programs, $124+3$ year programs, and 27 I-6 programs in the United States. ${ }^{1,2}$ Many US training programs offer a cardiothoracic pathway (focused on but not limited to cardiac surgery) and a general thoracic pathway (focused on but not limited to general thoracic surgery). Although these pathways have separate case requirements, there are no differences in the ABTS certification process or the ACGME accreditation process.

In 1928, the first $5+2$ cardiothoracic training program was opened at the University of Michigan. ${ }^{3}$ This track required completion of a 5-year general surgery residency, followed by 2 years of cardiothoracic training. However, as cardiothoracic surgery evolved to include a wider spectrum of diseases and procedures, some educators felt that 2 years was not enough time to teach the requisite skill set. In response, the first $5+3$ programs were introduced in the late 1950s. Currently, traditional cardiothoracic training programs are either a $5+2$ or $5+3$ program, at the discretion of the program leadership and the Accreditation Council on Graduate Medical Education Resident Review Committee (RRC).

In the mid-2000s, multiple forces contributed to the development of new cardiothoracic surgical training 
TABLE 1. Program Elements for General Thoracic Training in Canada and the United States

\begin{tabular}{|c|c|c|}
\hline & Canada & United States \\
\hline $\begin{array}{l}\text { Number of accredited } \\
\text { training programs }\end{array}$ & 8 & 109 \\
\hline $\begin{array}{l}\text { Number of active } \\
\text { residents per year }\end{array}$ & $12-15$ & 395 \\
\hline $\begin{array}{l}\text { Prerequisite training } \\
\text { for entry }\end{array}$ & $\begin{array}{l}\text { RCPSC certification after graduating general } \\
\text { or cardiac surgery }\end{array}$ & $\begin{array}{l}5+2 \text { or } 5+3 \text { programs: General surgery } \\
4+3 \text { or I- } 6 \text { programs: Medical school }\end{array}$ \\
\hline Governing body & RCPSC & ACGME \\
\hline Tenants of training & $\begin{array}{l}\text { RCPSC CanMEDS elements: } \\
\text { medical expert, professional, communicator, } \\
\text { collaborator, leader, health advocate, } \\
\text { scholar }\end{array}$ & $\begin{array}{l}\text { Six core competencies: patient care, medical knowledge, } \\
\text { practice-based learning and improvement, interpersonal } \\
\text { communication skills, professionalism, and system-based practice }\end{array}$ \\
\hline Use of simulation & $\begin{array}{l}\text { 4-day national simulation bootcamp, attended } \\
\text { by all first-year trainees }\end{array}$ & $\begin{array}{l}\text { One resident per program nominated to attend TSDA boot camp; all } \\
\text { residents required to perform }>20 \mathrm{~h} \text { simulation during training }\end{array}$ \\
\hline $\begin{array}{l}\text { Program yearly } \\
\text { structure }\end{array}$ & $\begin{array}{l}\text { Two-year secondary residency, following } \\
\text { 5-year general surgery or cardiac residency }\end{array}$ & $\begin{array}{l}5+2 \text { or } 5+3 \text { programs: } 2 \text { or } 3 \text { y after general surgery } \\
4+3 \text { programs: } 4 \text { y of general surgery and } 3 \text { y of cardiothoracic surgery } \\
\text { I- } 6 \text { programs: medical school followed by } 6 \text { y of cardiothoracic surgery }\end{array}$ \\
\hline Rotations & $\begin{array}{l}18 \text { mo general thoracic, } 3 \text { mo cardiovascular, } \\
3 \text { mo elective }\end{array}$ & Varies by program \\
\hline $\begin{array}{l}\text { Certification } \\
\text { requirements }\end{array}$ & $\begin{array}{l}\text { Successful final in-training evaluation by } \\
\text { residency committee, completion of } \\
\text { written and Oral RCPSC examination } \\
3 \text { mo after graduation }\end{array}$ & $\begin{array}{l}\text { Minimum case number requirement, program director attestation, written } \\
\text { qualifying and oral ABTS exams after graduation }\end{array}$ \\
\hline $\begin{array}{l}\text { Postgraduation } \\
\text { certification }\end{array}$ & $\begin{array}{l}\text { No formal examinations/evaluations. Annual } \\
\text { submission of Continuing Medical } \\
\text { Education hours to RCPSC }\end{array}$ & $\begin{array}{l}\text { Maintenance of Certification by the ABTS requires: a secure exam every } \\
10 \mathrm{y} \text {, good professional standing, documentation of Continuing Medical } \\
\text { Education hours, peer evaluation and a quality improvement project }\end{array}$ \\
\hline
\end{tabular}

paradigms that did not require a full 5 years of general surgery training. Prime among these forces were technical developments in cardiac surgery that made general surgical training less valuable and concerns about the duration of training being a deterrent for potential applicants to the specialty. Fewer residents were applying to cardiothoracic residency programs than ever before, despite exciting advances in the field, a growing elderly population, and the rapid rate of cardiothoracic surgeon retirement. ${ }^{4,5}$ This decline in applications was occurring in the face of projections that the demand for cardiothoracic surgeons would increase by as much as $46 \%$ by $2025 .{ }^{4}$ In response, the Joint Training Program model $(4+3)$ was approved by the ACGME in 2006. This is a 7-year track for residents already matched in a general surgery training program that allows the resident to complete a total of 4 years of general surgery and 3 years of cardiothoracic surgery, with board eligibility in both specialties: the American Board of Surgery and the ABTS. Residents apply in the general surgery match at an institution with a $4+3$ program, express interest in cardiothoracic surgery, and then apply to participate in the Joint Training Program, which begins after the third clinical year.
Integrated training programs existed in the United States in several institutions before 1990, but by 1994 the ABTS precluded this pathway. A different manifestation of integrated program was subsequently developed and endorsed by the ABTS, and the first I- 6 cardiothoracic surgery program was approved at Stanford University in 2007. ${ }^{6}$ In this model, residents are accepted directly out of medical school and learn from a cardiothoracic surgery-focused curriculum over 6 years. The first 2 to 3 years consist of an introduction to core surgical specialties, similar to general surgical training, and include exposure to cardiothoracic surgery. The final 3 to 4 years provide surgical specialization in cardiothoracic surgery. The purpose of this model was not to shorten training from the traditional 7 to 8 years but to integrate formal rotations in medical and surgical cardiothoracic specialties directly relevant to modern cardiothoracic surgical practice. To this end, the experience includes interventional cardiology, interventional radiology, heart failure, critical care, cardiac anesthesia, vascular and endovascular surgery, as well as traditional rotations in adult cardiac, congenital cardiac, general thoracic, and general surgery. The overarching goal of the I-6 training paradigm is to provide more 
comprehensive training in all aspects of cardiovascular and thoracic diseases through true multidisciplinary training.

The majority of the I-6 training programs focus their training for residents who are interested in the cardiothoracic pathway, as opposed to the general thoracic pathway. The first I-6 residents graduated in 2013, and there are limited data to assess the efficacy of this model. It is, however, unlikely that the traditional $5+2$ and $5+3$ pathways will be replaced, as many residents continue to have their first exposure to cardiothoracic surgery during general surgery training, ultimately leading to their decision to pursue a career in the field. Residents who complete an I-6 program are eligible for ABTS certification but not American Board of Surgery certification.

\section{Canada}

There has been considerable change over the years, but general thoracic surgical training programs in Canada are generally more uniform than in the United States ${ }^{7}$ and are most analogous to the 2-year component of traditional "5 +2 " programs in the United States. All applicants will have completed a formal 5- or 6-year residency in either general surgery or cardiac surgery before entry, with the vast majority arising from general surgery. There are currently 8 general thoracic surgery residency programs accredited by the Royal College of Physicians and Surgeons of Canada (RCPSC), each training 1 or 2 residents per year, producing 6 to 8 graduates nationally per year. The general thoracic residency program spans 2 full academic calendar years, commencing July 1 . Residents first rotate through their "junior residency" in their first year and, if successful, are promoted to their "senior residency" in their second year. There is broad geographic representation, with a single program existing in the provinces of British Columbia, Alberta, Manitoba, and Quebec and 4 programs in Ontario. All programs exist within the confines of a university-based academic setting. Programs have some variations based on location, but in general the program structure, administration, curriculum, rotations, goals and objectives, and accreditation are quite rigidly defined and founded on the tenants of the RCPSC. The RCPSC explicitly defines what is required of the "Administrative Structure," "Goals and Objectives," "Structure and Organization of the Program," "Resources," "Clinical, Academic and Scholarly Content of the Program," and "Evaluation of Resident Performance." ${ }^{8}$ The RCPSC requires each program to have a single dedicated Program Director and Program Administrator, under the auspices of the respective Universities' Postgraduate Medical Education Dean's office. Each program must have a formal General Thoracic Surgery Residency Training Committee with documented meetings related to curriculum, evaluation, promotion, and safety.

\section{ENTRY INTO THORACIC SURGERY TRAINING PROGRAMS \\ United States}

Cardiothoracic surgery training programs in the United States (traditional and I-6) must participate in the National Residency Matching Program (NRMP). ${ }^{9}$ Through the Electronic Residency Application Service, applicants select training programs and submit their applications online. ${ }^{10}$ Program directors review the applications and select applicants to invite for an interview. At the conclusion of the application and interview process, both the training programs and the applicants generate rank-lists. These rank lists are submitted to the NRMP and trainees and programs are matched approximately 1 year before their planned start date. The NMRP developed The Match to allow residents and programs to consider each other without pressure, create a fair way to assign trainees to programs, and establish a single date for appointments to programs. The Match ensures all participants comply with a strict set of policies to avoid any "gaming" of the system or "side deals." 11

\section{Canada}

The requirements for entry into a Canadian thoracic surgery training program are outlined in detail on the RCPSC website. $^{12}$ The application deadline occurs 18 months before the commencement of training and is a fixed date, common to all programs. Each program manages applications independently, and there is no formal electronic matching system, unlike most primary residency programs in Canada, which use the electronic Canadian Resident Matching Service, which functions almost exactly like the NRMP program in the United States. ${ }^{13}$ Programs evaluate and interview candidates independently and provide offers to residents on a prespecified date in March. Because all thoracic residents will have completed a general or cardiac surgery residency, thoracic surgery residency is considered a subspecialty residency or a secondary residency. Ultimately, certification in their primary specialty is required before candidates can sit for the RCPSC exam in thoracic surgery. All programs extend over a 2-year period with a focus on general thoracic surgery (18 months) and cardiac surgery (3-4 months). Although not the focus of this review, cardiac surgery is a primary residency in Canada that residents enter directly following medical school, through the Canadian Resident Matching Service match. Cardiac surgery residents must spend a minimum of 3 months rotating through general thoracic surgery as senior residents. In addition to the formal 2-year residency in thoracic surgery culminating in RCPSC certification, there are a few programs with true subspecialty, nonaccredited, 1-year fellowship programs in general thoracic surgery, transplantation or advanced endoscopy. 


\section{PROGRAM CORE OBJECTIVES United States}

Historically, advancement in US cardiothoracic training programs was based on the length of time spent in the program. Over the last decade, there has been a shift toward competency-based advancement. In 2006, the ACGME identified 6 core competencies, these being patient care, medical knowledge, practice-based learning and improvement, interpersonal communication skills, professionalism, and system-based practice that residents are judged on by faculty, their peers, and ancillary staff. The 6 competencies are used as a foundation for establishing "milestones" specific to cardiothoracic surgical training. The ACGME has defined 26 categories for mastery during cardiothoracic training, ranging from Lung and Airway to Great Vessel Disease, and each category has a list of milestones that describe the desired knowledge, skills, and attitudes a resident should strive to acquire. ${ }^{14}$ Residents are evaluated on a semiannual basis, and the milestone level that best describes their current performance in each competency is reported to the ACGME. The milestones levels are organized from less (Level 1, novice) to more advanced (Level 5, expert) (Table 2). Level 4 is designated as the graduation target but is not a graduation requirement. The decision to graduate a resident remains at the discretion of the residency program director. The use of competency-based assessment reflects an understanding that residents do not all progress at the same rate, and the overall duration of training may eventually depend on accomplishment of specific objectives.

\section{Canada}

All Canadian thoracic training programs are overseen by the RCPSC and are structured according to a single formal

TABLE 2. Levels of competency defined by the Accreditation Council for Graduate Medical Education (ACGME) Milestones Project ${ }^{12}$

Level 1 The resident demonstrates milestones expected of an incoming resident.

Level 2 The resident is advancing and demonstrates additional milestones but is not yet performing at a mid-residency level.

Level 3 The resident continues to advance and demonstrate additional milestones, consistently, including the majority of milestones targeted for residency.

Level 4 The resident has advanced so that he or she now substantially demonstrates the milestones targeted for residency. This level is designed as the graduation target.

Level 5 The resident has advanced beyond performance targets set for residency and is demonstrating "aspirational" goals, which might describe the performance of someone who has been in practice for several years. It is expected that only a few exceptional residents will reach this level. national set of "Objectives of Training." 15 The current National Thoracic Curriculum is based on the RCPSC CanMEDS physician competency framework, called "CanMEDS 2015." ${ }^{16}$ Analogous to the competencies identified by the ACGME, the CanMEDS framework defines distinct roles of expertise that graduates must obtain under the domains of Medical Expert, Communicator, Collaborator, Scholar, Professional, Leader and Health Advocate. ${ }^{16,17}$ The RCPSC Subspecialty Committee in Thoracic Surgery has developed a National Curriculum Guide to complement the Objectives of Training, which provides detailed structure for academic activities. ${ }^{18}$

The RCPSC recognizes 82 accredited "disciplines," and all of them are in the midst of transitioning to a formal Competency-Based Medical Education (CBME), entitled "Competency by Design" over a 5-year cycle, with the 2017/2018 academic year serving as the first roll-out for a limited number of residencies such as otolaryngology and medical oncology. This paradigm shift has been introduced by the RCPSC with the general concept that, unlike the traditional time-based apprenticeship training, the CBME model requires trainees to progress through "Milestones" with measurable and defined "Entrustable Professional Activities" (EPA) based on gradational skill development, independent of time. A milestone is an observable marker of an individual's ability along a developmental continuum, where an EPA is a task of the discipline. Typically, each EPA integrates multiple milestones. ${ }^{19}$ The RCPSC Subspecialty Committee in Thoracic Surgery and the Program Directors will collectively define and develop the EPAs, as well as their respective evaluations, through an interactive team-based approach, facilitated by a series of in-person meetings in the 1 year leading up to the CBME roll-out. The RCPSC has a staff or CBME experts and facilitators whom work with the subspecialty committee on this task. It is anticipated that thoracic surgery residencies will be fully CBME modeled beginning in 2020 .

\section{RESIDENCY CONTENT AND ROTATIONS United States}

Rotation schedules at each US training program vary depending on the length of the program and institutional clinical volume. Residents must meet minimum case requirements in either the cardiothoracic or general thoracic surgery pathway to be eligible for the ABTS examinations (Table 3). By the end of their training, residents are expected to function as independent surgeons in all aspects of adult cardiac and general thoracic surgery, regardless of their specific pathway.

Simulation has taken on a larger role in US cardiothoracic training programs. Since 2008, the Thoracic Surgery Directors Association (TSDA) has held an annual "boot camp," where first-year traditional residents and fourthyear integrated residents perform guided simulation of 
TABLE 3. 2017 American Board of Thoracic Surgery Case Requirements ${ }^{20}$

\begin{tabular}{|c|c|c|c|c|}
\hline \multicolumn{2}{|c|}{ Cardiothoracic focused } & \multirow[b]{2}{*}{ Requirements } & \multicolumn{2}{|c|}{ General thoracic focused } \\
\hline Total & Subtotal & & Subtotal & Total \\
\hline & & Congenital heart disease & & \\
\hline & 5 & Primary surgeon & & \\
\hline & 15 & First assistant & 10 & \\
\hline \multirow[t]{2}{*}{20} & & Subtotal congenital heart disease & & 10 \\
\hline & & Adult cardiac & & \\
\hline \multirow[t]{6}{*}{60} & & Acquired valvular heart disease & & 30 \\
\hline & 25 & Aortic valve repair/replacement & 15 & \\
\hline & 15 & Mitral valve repair/replacement & 5 & \\
\hline & 5 & Tricuspid valve repair/replacement, annuloplasty & 5 & \\
\hline & 5 & TAVR as primary & & \\
\hline & 10 & TAVR as assistant & 5 & \\
\hline \multirow[t]{2}{*}{80} & & Myocardial revascularization & & 35 \\
\hline & 15 & Re-do sternotomy* & 5 & \\
\hline \multirow[t]{3}{*}{15} & & Interventional wire-based procedures & & 5 \\
\hline & 5 & Left heart catheterization, PCI, TEVAR, mitral clip & & \\
\hline & 10 & Intra-aortic balloon pump & 5 & \\
\hline 5 & & $\begin{array}{l}\text { Conduit dissection and preparation } \dagger \\
\text { Open or endoscopic saphenous/radial vein harvest and preparation }\end{array}$ & & 5 \\
\hline 10 & & $\begin{array}{l}\text { Aortic procedures } \ddagger \\
\text { Any combination of ascending aorta/aortic root replacement, descending aortic } \\
\text { replacement, aortic dissection, aortic trauma }\end{array}$ & & 5 \\
\hline \multirow[t]{3}{*}{10} & & Arrhythmia surgery§ & & \\
\hline & 5 & $\begin{array}{l}\text { Left atrial or biatrial maze, pulmonary vein isolation, right-sided maze, isthmus } \\
\text { ablation }\end{array}$ & & \\
\hline & 5 & Pacemaker insertion or pacemaker removal & & \\
\hline 5 & & Cardiopulmonary bypass set-up and pump run with perfusionist & & 5 \\
\hline 10 & & $\begin{array}{l}\text { Circulatory assist } \| \\
\text { Any combination of ECMO, VAD }\end{array}$ & & 5 \\
\hline \multirow[t]{2}{*}{195} & & Subtotal adult cardiac experience & & 90 \\
\hline & & General thoracic & & \\
\hline \multirow[t]{4}{*}{60} & & Lung & & 105 \\
\hline & 30 & $\begin{array}{l}\text { Major anatomic resections: open, VATS, or RATS (segmentectomy, lobectomy, } \\
\text { pneumonectomy, lung transplantation } \uparrow \text { ) }\end{array}$ & 50 & \\
\hline & 5 & VATS/RATS lobectomy specifically & 25 & \\
\hline & 25 & Open or VATS lung biopsy/wedge resection & 30 & \\
\hline \multirow[t]{4}{*}{10} & & Pleura & & 25 \\
\hline & & $\begin{array}{l}\text { Major (empyema decortication, pleurectomy decortication, other pleural tumor } \\
\text { resection) }\end{array}$ & 5 & \\
\hline & & $\begin{array}{l}\text { Minor (biopsy, pleurectomy, VATS sympathectomy, VATS bleb resection, VATS } \\
\text { pleurodesis, evacuation of hemothorax) }\end{array}$ & 15 & \\
\hline & & Interventional: in-dwelling cuffed pleural catheter insertion & 5 & \\
\hline
\end{tabular}


TABLE 3. Continued

\begin{tabular}{|c|c|c|c|c|}
\hline \multicolumn{2}{|c|}{ Cardiothoracic focused } & \multirow[b]{2}{*}{ Requirements } & \multicolumn{2}{|c|}{ General thoracic focused } \\
\hline Total & Subtotal & & Subtotal & Total \\
\hline \multirow[t]{2}{*}{5} & & Chest wall and diaphragm & & 10 \\
\hline & & $\begin{array}{l}\text { Chest wall resection,\# rib resection, rib plating, pectus repair, diaphragm resection } \\
\text { or plication, repair of Morgagni, Bochdalek, traumatic hernia }\end{array}$ & & \\
\hline \multirow[t]{2}{*}{5} & & Mediastinum & & 10 \\
\hline & & Tumor/cyst/mass resection via open, VATS, or robotic technique & & \\
\hline \multirow[t]{2}{*}{0} & & Tracheobronchial - airway surgery** & & 5 \\
\hline & & $\begin{array}{l}\text { Tracheal resection, laryngotracheal resection, sleeve lobectomy, carinal } \\
\text { pneumonectomy, transplantation airway anastomosis }\end{array}$ & & \\
\hline \multirow[t]{4}{*}{10} & & Esophagus & & 35 \\
\hline & 5 & Esophagectomy (open or MIE) & 20 & \\
\hline & 5 & $\begin{array}{l}\text { Benign esophagus-repair of perforation, drain perforation, diverticulectomy, } \\
\text { myotomy, hiatal hernia repair }\end{array}$ & 10 & \\
\hline & & Laparoscopic hiatal or paraesophageal repair & 5 & \\
\hline 90 & & Subtotal general thoracic experience & & 190 \\
\hline \multirow[t]{2}{*}{305} & & Total major operative experience & & 290 \\
\hline & & Minor procedures $\dagger \dagger$ & & \\
\hline \multirow[t]{3}{*}{30} & & Bronchoscopy & & 40 \\
\hline & & Simple (BAL, diagnostic, TBBx, Bx) & 30 & \\
\hline & & $\begin{array}{l}\text { Complex (laser, dilation, stent, navigational bronchoscopy, photodynamic therapy, } \\
\text { cryotherapy) }\end{array}$ & 10 & \\
\hline \multirow[t]{3}{*}{10} & & UGI endoscopy & & 30 \\
\hline & & Simple (diagnostic, Bx) & 20 & \\
\hline & & Complex (dilation, stent, EUS, EMR) & 10 & \\
\hline \multirow[t]{4}{*}{15} & & Mediastinal assessment & & 55 \\
\hline & 5 & Mediastinoscopy, chamberlain (mediastinotomy) & 15 & \\
\hline & & EBUS/FNA & 10 & \\
\hline & 10 & Mediastinal node dissection/systematic sampling during lung resection & 30 & \\
\hline \multirow[t]{2}{*}{55} & & Subtotal minor procedures & & 125 \\
\hline & & Additional requirements & & \\
\hline \multirow[t]{3}{*}{50} & & Consultation experience & & 50 \\
\hline & 25 & New patients & 25 & \\
\hline & 25 & Follow-up patients & 25 & \\
\hline \multirow[t]{2}{*}{20} & & Multidisciplinary patient management conferences & & 20 \\
\hline & & $\begin{array}{l}\text { Any combination of tumor board, cardiac catheterization conference, } \\
\text { multidisciplinary clinics, transplant selection committee meetings, etc. }\end{array}$ & & \\
\hline \multirow[t]{4}{*}{75} & & Cardiothoracic critical care case management experience & & 75 \\
\hline & 20 & General thoracic & 20 & \\
\hline & 20 & Cardiac and congenital & 20 & \\
\hline & 35 & Any additional cardiothoracic critical care case & 35 & \\
\hline $20 \mathrm{~h}$ & & $\begin{array}{l}\text { Simulation (hours required from any technique-based simulation curriculum or } \\
\text { simulation of cardiopulmonary bypass management) }\end{array}$ & & $20 \mathrm{~h}$ \\
\hline
\end{tabular}

$\overline{T A V R}$, Transcatheter aortic valve replacement; $P C I$, percutaneous coronary intervention; TEVAR, thoracic endovascular aortic repair; $E C M O$, extracorporeal membrane oxygenation; $V A D$, ventricular assist device; VATS, video-assisted thoracoscopic surgery; $R A T S$, robotic-assisted thoracoscopic surgery; $M I E$, minimally invasive esophagectomy; $B A L$, bronchoalveolar lavage; $T B B x$, transbronchial lung biopsy; $B x$, biopsy; $U G I$, upper gastrointestinal series; $E U S$, endoscopic ultrasonography; $E M R$, endoscopic mucosal resec-

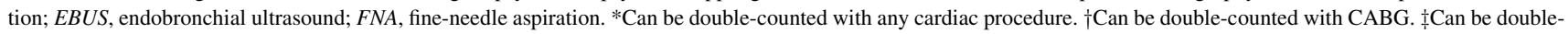
counted with CABG/valve procedures. §Can be double-counted with CABG/valve procedures. \|Can be double-counted with another operation. $\uparrow$ Only 1 pneumonectomy can be counted along with bilateral lung transplant. \#Can be double-counted with pulmonary resection. **Sleeve lobectomy and carinal pneumonectomy can be double-counted with major anatomic lung resection. $\dagger \dagger$ All may be double-counted. 
various skills. In addition, the Joint Council on Thoracic Surgery Education and TSDA have developed a simulation curriculum. To be eligible for the ABTS examination, cardiothoracic residents are required to have at least 20 hours of simulation time.

With technological advancements, online resources have become increasingly used. In 2016, the Joint Council on Thoracic Surgery Education launched an online resource for US trainees called the "Learning Management System" (LMS), ${ }^{21}$ which is managed by the Society of Thoracic Surgeons. The LMS allows program directors to assign reading materials from a broad library of texts, journal articles, and videos as well as to customize a reading schedule based on the Thoracic Surgery Curriculum. Program directors can set up a 1-, 2-, or 3-year curriculum, upload unique content and assignments, track resident progress on assignments, and offer National Benchmarked Quizzes to their residents that allow comparison with residents across the country. Importantly, the information available through the LMS mirrors that used by the ABTS to create its exams.

Each year, all US cardiothoracic trainees take the TSDA in-training examination (ITE). The ITE assesses the knowledge of cardiothoracic residents and helps them prepare for the ABTS exam. It also allows program directors to gauge acquisition of residents' knowledge throughout training but it is not designed to be used as a benchmark for promotion or graduation.

\section{Canada}

Canadian thoracic residency takes place over a 2-year cycle. In the first year, junior thoracic residents typically spend a minimum of 6 months on the general thoracic surgical service, with an additional 3 months on cardiac surgery, and 2 to 3 months of elective time that can be taken in first or second year. Elective time may consist of rotations in a variety of areas including transplantation, interventional pulmonology, community-based thoracic surgery, or research. Although Canadian residents do cardiac surgery rotations, they are not accredited as cardiovascular surgeons at the conclusion of their residency. In the second year, residents will typically spend 10 to 12 months on general thoracic surgery rotations. A typical general thoracic resident's week will consist of a half-day of endoscopy/ bronchoscopy, a half-day of outpatient clinics, 3.5 days of operating room experience, and a protected academic half-day. This academic half-day must be free from all clinical and on-call duties. The "half-day" consists of weekly seminars covering the National Curriculum, independent study time, and research. In addition to this time, residents develop their skills as "leaders" and "collaborators" as they participate in weekly lung and esophageal tumor boards, monthly morbidity and mortality rounds, quality assurance rounds, and educational rounds from other disciplines.
Since 2014, a 4-day general thoracic surgery boot camp has taken place at the University of Toronto. The boot camp curriculum was developed collaboratively, and resident attendance is considered mandatory by all training programs. The boot camp delivers high-fidelity, hands-on wet-lab simulation in performing more than 15 procedures, including foregut surgery (fundoplication, esophageal myotomy, per oral endoscopic myotomy), pulmonary surgery (thoracoscopic lobectomy, airway, and vascular anastomosis), interventional airway procedures (rigid bronchoscopy, stent placement, endobronchial ultrasound), and crisis management. ${ }^{22,23}$ Feedback from participants in the first 4 years has been positive with respect to educational value and technical exposure.

Unlike in the United States, there are no predefined "procedural case-volume requirements" for Canadian thoracic surgery graduates, and the RCPSC does not publish the individual case-volumes of its graduates. However, in Canada the delivery of thoracic surgical care has been concentrated into a smaller number of regional centers of excellence, and the residency programs are all situated in these high-volume centers. Graduating residents will have amassed a large procedural case experience over 2 years, generally performing between 550 and 700 major operative cases and 100 and 200 endoscopies reported (Dr Schieman, personal communication, August 2018).

\section{ACCREDITATION AND POSTGRADUATION PRACTICE \\ United States}

Accreditation of US cardiothoracic surgery training programs is performed by the ACGME. The Next Accreditation System (NAS) was designed by the ACGME to allow for electronic evaluation of programs, with site visits reserved for new programs or programs that do not meet benchmark criteria. ${ }^{24}$ The NAS requires annual compliance assessments in which key performance measures are evaluated. The NAS was developed to focus on outcomes, allow good programs to be innovative, and help underperforming programs to improve. Instead of scheduled site visits at the end of a predefined "cycle length," programs submit outcomes data annually that are reviewed by the RRC. The accreditation status and citations can be changed on an annual basis. However, Clinical Learning Environment Review site visits are intermittently performed by the RRC to critically examine the learning environment at individual training sites. The NAS includes evaluation of milestone performance, resident and faculty surveys, and case log data. Programs conduct a self-study before each scheduled site visit to allow meaningful discussion of what is important to the program and showcasing of achievements in key program elements and learning outcomes. ${ }^{24}$

When residents complete a training program in good standing and have met the ABTS requirements, they 
become eligible to take the ABTS qualifying (written) examination. Upon passing the qualifying exam, they may take the oral certifying examination approximately 6 months later. In 2017, 126 candidates took ABTS qualifying exam (written), with an $89 \%$ pass rate, and in 2017 , 130 candidates took the certifying exam (oral), with an $84 \%$ pass rate (personal communication, Patricia Watson, American Board of Thoracic Surgeons, November 21, 2016).

The TSRA surveys all cardiothoracic trainees during the ITE every year. Based on the survey taken in $2014,60 \%$ of trainees had undergone job interviews in mixed cardiothoracic private practice, $43 \%$ in academic cardiac practice, $43 \%$ in private cardiac practice, $40 \%$ in academic thoracic practice, $39 \%$ in private thoracic practice, and $22 \%$ in mixed academic cardiothoracic practice. ${ }^{25}$

\section{Canada}

Accreditation relates to both the individual residents as well as to the training programs. Accreditation of individual training programs is granted by the RCPSC and occurs on a 6-year cycle with alternating internal and external reviews every 3 years. The RCPSC enlists a review team, typically consisting of 2 senior surgical specialists outside of the discipline of interest as well as a resident from different program. The accreditation is a highly prescriptive and exhaustive process wherein the academic and administrative structure of the program takes place over 1 to 2 days, with the review team ultimately providing a recommendation to the RCPSC. ${ }^{26}$ Programs must demonstrate that all of the RCPSC goals and objectives are complied with, that the National Curriculum is delivered, that assessment is timely and multifaceted, and that the program director, residents, and program administrators have the resources required to succeed.

At the completion of the 2-year residency, each resident receives a final in-training evaluation report authored by the local Thoracic Residency Training Committee. Trainees who have passed their final in-training evaluation report are eligible to take the RCPSC examination 3 months later. The exam is overseen by the RCPSC Thoracic Surgery Examinations Committee and consists of a written and oral examination taken closely together. Those who pass the RCPSC examination then receive Thoracic Surgery Specialty Certification. Upon successful graduation from general thoracic surgery in Canada, surgeons are certified to practice "thoracic surgery" and are not qualified or given privileges to perform cardiac surgery. A survey of all Canadian general thoracic surgery residents in 2009 indicated $16 \%$ intended to take additional training following graduation, with $67 \%$ planning to practice exclusively in general thoracic surgery (as opposed to mixed-general surgery and thoracic surgery), with $58 \%$ desiring to practice in a university based-teaching hospital. ${ }^{27}$

\section{FUTURE CHALLENGES United States}

There are many challenges that face cardiothoracic surgery training in the United States. Society has increasingly demanded transparency in surgical outcomes, making the "see one, do one, teach one" model obsolete. In addition, the majority of trainees today are more aware of the importance of balancing work and lifestyle. As the knowledge base and surgical skills required to become a competent cardiothoracic surgeon grow, educators in the United States will try to determine the best training paradigms for trainees. Many believe that the I- 6 program is the ideal model for training cardiac surgeons. As well, the $4+3$ program may be the best model for general thoracic surgeons; however, the $4+3$ model requires a level of cooperation between general surgery and thoracic surgery training programs that is reached in a limited number of institutions.

It is possible that cardiac and general thoracic surgeons will eventually achieve ABTS certification through different examinations, even though current training paradigms may not change. For the foreseeable future, the ABTS will be responsible for the certification of both cardiac and general thoracic surgeons. It is still common for residents to shift focus from one specialty to another; a large number of surgeons still practice both cardiac and general thoracic surgery; and the political influence of the specialty of cardiothoracic surgeons in the United States is enhanced by cardiac and general thoracic surgeons remaining united.

\section{Canada}

Thoracic surgery in Canada similarly faces many challenges, the greatest of which is a nationwide CBME program entitled Competency by Design (CBD), changes in the breadth and scope of thoracic surgical disease and treatment, and accurately forecasting thoracic workforce requirements. Despite the groundswell in enthusiasm for $\mathrm{CBD}$, it remains to be seen how residents will progress through a competency-based curriculum. Questions remain as to how thoracic surgery competencies will be properly evaluated and whether the quality of the graduating CBD trainee will be superior to the current graduating residents. Lastly, as a result of a multitude of factors, many surgical disciplines are faced with unprecedented crises in surgical unemployment and workforce planning, particularly in orthopedic surgery and general surgery. ${ }^{28}$ The original Canadian Thoracic Manpower and Education study and the subsequent modeling of workforce needs have provided some insight in the future of employment situation. ${ }^{29}$ To date, a good match of trainees to available positions has existed. Recent workforce modeling studies suggests that with the current number of graduates (6-8 per year) the workforce needs for general thoracic surgeons in Canada should be met until $2030 .^{30,31}$ 
Public reporting of surgical outcomes is not currently conducted in Canada, although it is reasonable to imagine that will one day be a requisite for practice.

\section{CONCLUSIONS}

Both Canada and the United States are internationally recognized for producing highly skilled general thoracic surgeons. Despite their geographic proximity, similar histories, and similar socioeconomics, both countries have evolved distinctly different training systems for general thoracic and cardiothoracic surgeons. Increasingly, crossborder collaboration between Canadian and American surgeons, including bi-national representation on many governing agencies, including the TSDA and Society of Thoracic Surgeons, has evolved as both countries work together to overcome similar challenges for trainees and educators.

\section{Conflict of Interest Statement}

Authors have nothing to disclose with regard to commercial support.

\section{References}

1. Accreditation Council for Graduate Medical Education. List of programs by specialty. Available at: https://apps.acgme.org/ads/Public/Reports/Report/1. Accessed August 13, 2018.

2. Thoracic Surgery Directors Association. 4/3 Thoracic surgery residency programs. Available at: http://www.tsda.org/the-tsda/ct-residency-programs/43thoracic-surgery-residency-programs/. Accessed August 13, 2018.

3. Crawford F. Thoracic surgery education-past, present, and future. Ann Thorac Surg. 2005;79:S2232-7.

4. Grove A, Gorman K, Dall TM, Jonas R, Lytle B, Shemin R, et al. Shortage of cardiothoracic surgeons is likely by 2020. Circulation. 2009;120:488-94.

5. Merrill WH. Preparing the next generation of residents to care for patients with cardiothoracic disease. Tex Heart Inst J. 2012;39:878-9.

6. Rusch VW, Calhoon JH, Allen MS, Baumgartner W. The American Board of Thoracic Surgery: update. J Thorac Cardiovasc Surg. 2012;143:519-21.

7. Schieman C, Grondin SC. Thoracic surgery education in Canada. J Thorac Cardiovasc Surg. 2017;153:493-7.

8. Royal College of Physicians and Surgeons. Information by Discipline. Thoracic Surgery Subsection. Specific Standards of Accreditation for Residency Programs in Thoracic Surgery. Version 1.2 2014. Available at: http://www.royalcollege.ca/ $\mathrm{cs} /$ groups/public/documents/document/y2vk/mdaw/ edisp/tztest3rcpsced000472. pdf. Accessed February 122018.

9. National Resident Matching Program. Available at: http://www.nrmp.org. Accessed December 82016.

10. Electronic Residency Application Service. Available at: https://apps.aamc.org/ myeras-web. Accessed December 82016.

11. National Resident Matching Program. Intro the Fellowship Matches. Available at: http://www.nrmp.org/intro-fellowship-matches. Accessed August 10, 2018.

12. Royal College of Physicians and Surgeons. Information by Discipline. Thoracic Surgery Subsection. Specialty Training Requirements. Version 2.0; 2013.
13. Canadian Resident Matching Service. Available at: https://www.carms.ca/en. Accessed February 262018.

14. Thoracic Surgery Directors Association. Thoracic Surgery Milestones. Available at: http://www.tsda.org/education/thoracic-surgery-milestones. Accessed August 10, 2018.

15. Royal College of Physicians and Surgeons. Information by Discipline. Thoracic Surgery Subsection. Objectives of Training in the Subspecialty of Thoracic Surgery. Version 1.12010 . Available at: http://www.royalcollege.ca/cs/groups/ public/documents/document/y2vk/mdaw/ edisp/tztest3rcpsced000459.pdf. Accessed December 2016

16. Frank JR, Danoff D. The CanMEDS initiative: implementing an outcomes-based framework of physician competencies. Med Teach. 2007;29:642-7.

17. Royal College of Physicians and Surgeons of Canada. The CanMEDS Framework. Available at: http://www.royalcollege.ca/rcsite/canmeds-e. Accessed December 2016.

18. Royal College of Physicians and Surgeons. Information by Discipline. Thoracic Surgery Subsection. National Curriculum Guide for Thoracic Surgery. Available at: http://www.royalcollege.ca/cs/groups/public/documents/document/mdaw/ mdyy/ edisp/062201.pdf. Accessed February 2018.

19. Royal College of Physicians and Surgeons. EPAs and Milestones. Available at: http://www.royalcollege.ca/rcsite/cbd/implementation/cbd-milestones-epas-e. Accessed February 262018.

20. American Board of Thoracic Surgery. Index Case Requirements. Available at: https://www.abts.org/ABTS/Initial_Certification/Operative_Requirements/Index \% 20Case\%20Requirements-2017.aspx. Accessed February 262018.

21. The Society of Thoracic Surgeons. Available at: http://learnctsurgery.sts.org/lms/ home. Accessed December 8, 2016.

22. Continuing Professional Development, University of Toronto. Training Program Interventional Thoracic Surgery. Available at: http://www.cpd.utoronto.ca/its/. Accessed December 12, 2016.

23. Schieman C, Ujiie H, Donahoe L, Hanna W, Malthaner R, Turner S, et al. Devel oping a national simulation-based, surgical skills bootcamp in general thoracic surgery. J Surg Educ. 2018;75:1106-12.

24. Nasca TJ, Philibert I, Brigham T, Flynn TC. The next GME accreditation systemrationale and benefits. N Engl J Med. 2012;366:1051-6.

25. The Thoracic Surgery Directors Association. Frequently Asked Questions. Available at: http://www.tsda.org/the-tsda/ct-residency-programs/frequently-askedquestions. Accessed November 122016.

26. Royal College of Physicians and Surgeons of Canada. Accreditation of postgraduate medical training programs. Available at: http://www.royalcollege.ca/rcsite/ education-strategy-accreditation-e. Accessed August 10, 2018.

27. Schieman C, Kelly E, Gelfand G, Graham A, McFadden S, Edwards J, et al Thoracic surgery training in Canada according to the residents: the thoracic surgery resident survey, of the Canadian thoracic manpower and education study (TMed). J Surg Educ. 2010;67:325-34.

28. Wakeam E, Feinberg S. Surgeon unemployment: would practice sharing be a viable solution. Can J Surg. 2016;59:141-2.

29. Grondin SC, Schieman C, Kelly E, Darling G, Maziak D, Palacios MacKay M, et al. A look at the thoracic surgery workforce in Canada: how demographics and scope of practice may impact future workforce needs. Can J Surg. 2013; 56:E75-81.

30. Edwards JP, Schofield A, Oddone Palucci E, Schieman C, Kelly E, Servatyari R, et al. Identifying areas of weakness in thoracic surgical residency training: a comparison of the perceptions of residents and program directors. J Surg Educ. 2014; 71:360-6.

31. Edwards JP, Kelly E, Schieman C, Gelfand G, Grondin SC. Do new thoracic surgeons feel ready to operate? Self-reported comfort level of thoracic surgery trainees and junior thoracic surgeons with core thoracic surgery procedures. $J$ Surg Educ. 2011;68:270-81. 